\title{
Loving Mars: A Review of To Mars With Love, by Patricia Ann Straat
}

\author{
Christopher P. McKay
}

To Mars With Love, by Patricia Ann Straat, Palmetto Publishing Group, Charleston, SC, 2019, 304 pp, ISBN: 978-1-64111-147-8

$\mathbf{E}$ VERY SO OFTEN a book comes out that takes the reader behind the curtains to show how a major scientific endeavor came together out of the efforts of many people working over many years and overcoming many problems along the way. Here is that book for the Vikings on Mars.

The Viking Mission to Mars in 1976 remains to this day the only search for life on another world. Imagine what it must have been like to have designed and built one of the three biology instruments for that mission. That story is told here for the Labeled Release (LR) experiment by Patricia Ann Straat, one of the principal scientists on the LR.

The LR experiment was designed to accept a sample of martian soil and then add a small amount of water containing a few key organic compounds. The carbon atoms in these organic additives were radioactive. If something alive was present in the soil and metabolized the organic compounds, then radioactive gases, such as $\mathrm{CO}_{2}$, would be released. These radioactive gases could be detected with great sensitivity. It all sounds very straightforward and was in fact based on a rather simple laboratory procedure. But as Straat recounts, making this work autonomously on a spacecraft on Mars that would be millions of miles away was anything but straightforward. Most of the book is devoted to detailing the many problems, and their solutions, in the development of the final flight units of the LR that went to Mars on Viking lander 1 and 2. This is valuable both as a documentation of the way the LR operated and as a lesson in how hard it is to make even straightforward experiments work on another planet.

Although loaded with detail, the narrative moves along well, and the reader is caught up in the story of the LR development. It would have been quite suspenseful if the reader did not already know that the LR went to Mars and operated well. Straat is modest in her descriptions of the work, but it is clear that she was the heroine of this development and was committed, even obsessed, with getting the LR to Mars. Sometimes the narrative is interrupted by a story about the author's life outside the project. These stories may be interesting only to those that find them interesting, but they serve up a good lesson that I would encourage young scientists to absorb: One can work long and hard and achieve great results while still having a life outside of the laboratory.
Once on Mars, the LR operated as designed. If life was present, the expectation was that there would be a rapid release of radioactive gas. A second sample heated to a temperature high enough to kill microorganisms would be expected to generate no radioactive gas. And this is exactly the data that the LR experiment returned from Mars. Straat and her colleague in the development of the LR, Gil Levin, argued that this meant biology had been detected on Mars.

But not all the data sent back from Viking appeared consistent with a biology explanation. In particular, the instrument designed to detect organic molecules in the soil, a gas chromatograph mass spectrometer, reported nothing but low levels of, presumably Earth-based, contamination. It was hard to accept life without organics, and most scientists considered the LR results a chemical not biological phenomenon. This objection has been overcome by the discovery in 2007 of perchlorate on Mars by the Phoenix mission. The decomposition of perchlorate would have defeated the ability of the gas chromatograph mass spectrometer to detect organics after the sample was heated. But at the same time, the reactivity that derives from the perchlorate and its products could be a nonbiological explanation for the LR results.

Straat works the story through to these recent results providing an up-to-date analysis. But in the end she still favors a biological explanation for the LR results. Whether biology or not, this is a remarkable book, by a remarkable woman, about a remarkable instrument on the most remarkable mission ever to go to Mars.

\section{Editor Cady's Note About the Book}

Astrobiology readers interested in purchasing a limited edition hard copy version of the book can do so through https://www.tomarswithlove.com or by e-mailing info@tomars withlove.com

Address correspondence to: Christopher P. McKay NASA Ames Research Center Space Science Division 245-3 Moffett Field, CA 94035

E-mail: Chris.McKay@nasa.gov

NASA Ames Research Center, Moffett Field, California. 